\title{
Front contact optimization of industrial scale CIGS solar cells for low solar concentration using 2D physical modeling
}

Juan M. López-González ${ }^{\mathrm{a}^{*}}$, Albert Orpella ${ }^{\mathrm{a}}$, Jose-María Delgado-Sánchez ${ }^{\mathrm{b}}$, Emilio Sánchez-Cortezon ${ }^{\mathrm{b}}$, María D. Alba ${ }^{\mathrm{c}}$, Ramón Alcubilla ${ }^{\mathrm{a}}$

a Micro and Nano Technologies Group, Departament d'Enginyeria Electrònica, Universitat Politècnica de Catalunya,

C/ Jordi Girona 1-3, Mòdul C4, 08034 Barcelona, Spain

b Abengoa Solar New Technologies S.A.,

Parque Empresarial Soland Center, Ctra. A472 km 6, 41800 Sanlucar la Mayor Sevilla, Spain

${ }^{\mathrm{c}}$ Instituto Ciencia Materiales de Sevilla - (CSIC-US)

Avda. Americo Vespuccio 49, 41092 Sevilla, Spain

* Corresponding author. Tel +34 625080238, fax: +34 934054171; e-mail address: juan.lopez.gonzalez@upc.edu

\begin{abstract}
A 2D model for $\mathrm{Cu}(\mathrm{In}, \mathrm{Ga}) \mathrm{Se}_{2}$ (CIGS) solar cells under low solar concentration is described and contrasted with experimental data. Using simulation, the effect of front electric contact design parameters: finger width, finger separation, and number of buses are analyzed for solar concentrations from 1 up to 10 suns. Efficiency maps allowing front contact grid optimization are shown and analyzed for each concentration value, assessing the viability of CIGS solar cells for low concentration applications.
\end{abstract}




\section{Introduction}

Nowadays $\mathrm{CuIn}_{1-\mathrm{x}} \mathrm{Ga}_{\mathrm{x}} \mathrm{Se}_{2}$ (CIGS) is the most efficient thin film technology attracting great interest from the scientific community (Kaneshiro et al., 2010; Singh and Patra, 2010; Niki et al., 2010). Efficiencies exceeding 20\% have been obtained at the laboratory scale (Jackson et al., 2011) while the technology has reached an industrial maturity with efficiencies over $13 \%$ at the module level. Nevertheless the scarcity of In may limit the success of this technology and alternatives are being actively researched. Among them kesterites are candidates of choice although the technological complexities raise doubts about its industrial feasibility (Miskin, 2014).

Concentration may be an interesting alternative for CIGS technology because allows the reduction of cell area whereas the output power is maintained and consequently the use of rare and expensive materials could be minimized. However this field still largely unexplored. One of the reasons is the limiting effect of series resistance in thin film solar cells. When solar cell is operating under concentration level, series resistance is a critical issue, because photogenerated current density increases and electrode design becomes increasingly important in order to avoid ohmic losses.

Very little work has been done in concentration applications of CIGS solar cells. Some studies about small surface CIGS solar cells under high concentration have been performed (Paire et al., 2011, 2013; Ward et al, 2002), however in these range of dimensions - $<10^{-1} \mathrm{~cm}^{2}$ in [8] and $10^{-6} \mathrm{~cm}^{2}$ (Paire et al., 2011, 2013) - grid effects and in general series resistance are negligible due to the small dimensions of the cells.

The aim of this work is the optimization of the grid design through the exploration of the possible application of large surface CIGS solar cells in low solar concentration (LCPV) installations. 2D device simulator (ATLAS from SILVACO) (Silvaco, 2015) has been used. Firstly, and for tuning the model, the simulation results are validated for a large area CIGS based solar cell. Secondly, the capabilities of those cells under low solar concentration (up to 10 suns) have been explored optimizing the front contact grid (finger width, separation between fingers and number of buses) for each concentration. 


\section{Experimental details}

\subsection{Physical Characterization}

A reference solar cell based on CIGS thin-film technology was used. Cross section and geometry parameters are shown in Fig. 1 and Fig. 2, respectively. Silver fingers are 385 $\mu \mathrm{m}$ width separated $2330 \mu \mathrm{m}$. Active layers thicknesses are respectively: ITO $150 \mathrm{~nm}$, $\mathrm{Al}: \mathrm{ZnO} 200 \mathrm{~nm}, \mathrm{ZnO} 50 \mathrm{~nm}, \mathrm{CdS} 50 \mathrm{~nm}$ and CIGS $1500 \mathrm{~nm}$.

To obtain accurate simulation results it is necessary to have detailed knowledge about microstructure, composition, optical and electronic properties of involved materials. In particular, the Ga content is critical for the photovoltaic performance of the cell and needs to be known for a proper simulation. In order to assess this value, XRD and indepth resolved Raman Spectroscopy were performed.

XRD measurements were performed on the absorber samples (after etching of ITO and buffer layers) using a PANalytical X'Pert PRO MPD (model DY 3197) difractometer. The analysis was made between $10^{\circ}$ up to $75^{\circ} 2 \theta$.

In-depth resolved Raman-AES (Auger Electron Spectroscopy) measurements were performed on the absorber, using T64000 Horiba Jobin-Yvon spectrometer. Excitation was provided through the $514.5 \mathrm{~nm}$ emission line of an $\mathrm{Ar}+$ laser and measurements were performed in backscattering configuration. The penetration depth of scattered light in CIGS is estimated to be around $100 \mathrm{~nm}$. Combined in-depth Raman/AES measurements were made by sequentially acquiring a series of Raman spectra after sputtering the sample with the Ar+ beam from Phi 670 scanning Auger nanoprobe. To minimize damage in the sputtered region, the energy of the Ar+ beam during ion sputtering was below $5 \mathrm{keV}$

\subsection{Model description}


1D CIGS solar cells simulations have been previously reported (Huang, 2008). However, in a pure 1D model, some aspects of the solar cell, in particular those related with the collection of carriers at the front grid, cannot be analyzed. In this work we use a $2 \mathrm{D}$ simulator which allows the analysis of the device performance when the front grid design is modified. Materials and device structure varies in the vertical direction while the variation in the horizontal direction is going to be defined by the finger/bus geometry and distribution.

\section{Results}

\subsection{Microstructure and morphology}

Fig. 3 corresponds to a detailed image of the (112) CIGS XRD measured on the CIGS solar cell used in this work. This spectrum has a complex shape, resulting from the contribution of regions with different Ga relative content and can be fitted with three contributions corresponding to CIGS with $\mathrm{Ga} /(\mathrm{In}+\mathrm{Ga})$ fraction between $43 \%$ and $76 \%$. These compositions agree with the order of magnitude of the values range obtained from the in-depth resolved Raman measurements, as will be described later. Estimation of the relative Ga content is based on the assumption of the validity of Vegard's law, which predicts a linear dependence of the average lattice constant in the alloy with the relative Ga content. Then, in the modeling of the solar cell a gradual increase in the $\mathrm{Ga} /(\mathrm{In}+\mathrm{Ga})$ fraction content with thickness in the absorber will be used, from values about $33 \%$ at the surface up to a value of the order of $67 \%$.

Raman spectra have been measured after sputtering during different times, from the surface of the absorber down to the CIGS/Mo interface. These spectra are characterized by a dominant peak corresponding to the vibrational ground state A1 mode from the CIGS phase. The main feature in these spectra is the existence of a gradual blue shift of the A1 CIGS mode that increases with depth in the absorber, as shown in Fig. 4 (left). This blue shift is not accompanied by a corresponding increase of the Full Width at Half Maximum (FWHM) of the mode, as shown in this Figure (right). This allows to rule out a structural (disorder) related origin of the blue shift of the mode. Then, the shift has been attributed to a gradual increase in the relative $\mathrm{Ga} /(\mathrm{In}+\mathrm{Ga})$ content with the depth in the absorber, from values in the surface region about $33 \%$ up to a value of the order of 
$67 \%$. This agrees with the $\mathrm{Ga} /(\mathrm{In}+\mathrm{Ga})$ relative content values estimated at these regions from the XRD diffractogram (Fontané et al., 2009).

\subsection{Optical and electrical parameters}

Fig. 5 shows the complex refraction index for the semiconductor regions $(\mathrm{ZnO}, \mathrm{CdS}$, CIGS) (Chelvanathan et al, 2010; Gloeckler, 2005) used in the simulation of the optical behavior of the solar cell. In addition ITO layer is modeled with refraction real index equal to 2 .

Table 1 shows the used parameters for the different materials within the cell: Doping concentration $\left(\mathrm{N}_{\mathrm{D}} / \mathrm{N}_{\mathrm{A}}\right)$, relative dielectric constant $(\varepsilon)$, gap $(\mathrm{Eg})$, electronic affinity $(\chi)$, effective density of states both in conduction and valence bands $\left(\mathrm{N}_{\mathrm{c}}\right.$ and $\left.\mathrm{N}_{\mathrm{v}}\right)$, recombination lifetimes $\left(\tau_{\mathrm{n}, \text { eff }}\right.$ and $\left.\tau_{\mathrm{p} \text {,eff }}\right)$, carrier mobilities $\left(\mu_{\mathrm{n}}\right.$ and $\left.\mu_{\mathrm{p}}\right)$ and defect donor or acceptor like characteristics - a mid-gap gaussian defect continuous model is used (Hack et al., 1990, Silvaco, 2013) -, total density of states $\left(\mathrm{N}_{\mathrm{GD}}\right.$ or $\mathrm{N}_{\mathrm{GA}}$ ), peak energy $\left(\mathrm{E}_{\mathrm{GD}}\right.$ or $\left.\mathrm{E}_{\mathrm{GA}}\right)$, characteristic decay energy $\left(\mathrm{w}_{\mathrm{GD}}\right.$ or $\left.\mathrm{w}_{\mathrm{GA}}\right)$, electron capture cross-section $\left(\sigma_{\mathrm{eGD}}\right.$ or $\left.\sigma_{\mathrm{eGA}}\right)$, and hole capture cross-section $\left(\sigma_{\mathrm{hGD}}\right.$ or $\left.\sigma_{\mathrm{hGA}}\right)$.

ITO is considered in the simulation as a highly doped semiconductor with a $3.7 \mathrm{eV}$ gap (Mizrah and Adler, 1977) with a resistivity of $1000 \mu \Omega \mathrm{cm}$ (square resistance of $67 \Omega$ ), and a contact resistance with the metallic $\mathrm{Ag}$ fingers of $0.13 \Omega \mathrm{cm}^{2}$. Additionally, a surface recombination velocity at the interface CdS/ CIGS of $3 \cdot 10^{4} \mathrm{~cm} / \mathrm{s}$ has been taken into account. Since this work is mostly concerned with front grid optimization, the back contact has been substituted by a single metallic contact reproducing an effective contact resistance of $1.0 \Omega \mathrm{cm}^{2}$. The bidimensional structure in Fig. 1 is completed with an external resistance taking into account the experimentally measured resistivity of the fingers $(40 \mu \Omega \mathrm{cm})$ and the resistance introduced by the buses $(60 \mu \Omega)$.

Some of the parameters of Table 1 were extracted from the literature (Chelvanathan et al, 2010; Gloeckler, 2005). Other parameters like Ga composition in the absorbing layer has been measured through XRD and Raman/AES measurements as explained in the previous subsection and are graded approximately between 0.33 and 0.67 while the 
corresponding gap varies between 1.24 and $1.46 \mathrm{eV}$. This value has deep consequences in the quantum efficiencies for the high wavelength region of the solar spectrum and consequently in the short circuit current. Additionally the average value of the CIGS layer gap affects also the dark saturation current density and the open circuit voltage (Repins et al., 2006; Decock et al., 2011). The gap values within the CIGS layer and its dependence with Ga composition is a controversial question because some discrepancy exists between experimental and theoretical values (Lárez et al., 1994; Repins et al., 2006; Contreras et al., 2005; Ramanathan et al., 2005).

\subsection{Model validation}

As it was described in Chapter II, first step of the simulation consists to validate the model. It means that data obtained from the modeling will be compared with experimental data. For this purpose, a reference solar cell has been characterized using a solar simulator at different levels of concentration. Fig. 7 and Table 2 show the simulated and experimental results under different levels of sun concentration.

A good agreement between experimental and simulated data is observed. On the other hand a drastic reduction in efficiency is predicted and experimentally observed when going from 1 to 10 suns. This result demonstrate that front metallic grid of the solar cell needs to be properly designed to work under concentration; otherwise, the capabilities of the device are not well taken in advantage.

\subsection{Front contact optimization}

This section presents the effect on the solar cell efficiency of the following design parameters of the front electric contact: Finger width $a$, finger separation $s$, number of buses $n b$, for $\mathrm{x} 1, \mathrm{x} 2, \mathrm{x} 5, \mathrm{x} 7$ and $\mathrm{x} 10$ sun concentrations. The rest of geometrical parameters were fixed, $W=10 \mathrm{~cm}, L=21 \mathrm{~cm}, L_{b}=0.2 \mathrm{~cm}$, see Fig. 2 . 
Modeling will be performed in two scenarios: First, the effect of the number of buses is studied; secondly, the number of buses will be fixed to $3(n b=3)$ and finger width and finger separation will be modified.

Efficiencies for different number of buses from 1 to 7 and several values of finger separation $s$ and $a$ (finger separation and finger width) varying the solar concentration are shown in Table 3.

Although the optimum value seems to be 5 buses, there is a clear plateau between 3 and 7 buses for all values of concentration. Therefore, number of buses has been fixed to 3 .

Fig. 7 shows the simulated efficiency maps for 1 sun (Fig. 7a), x2 suns (Fig. 7b), x5 suns (Fig. 7c) and x10 suns (Fig. 7d) obtained as a function of finger width and separation. Figures for $\mathrm{x} 1$ or $\mathrm{x} 2$ suns and for $\mathrm{x} 1$ or $\mathrm{x} 10$ suns have different vertical axe scales in order to show clearly the optimized efficiency regions.

For $\mathrm{x} 1, \mathrm{x} 2, \mathrm{x} 5$, and $\mathrm{x} 10$ suns, the optimum efficiency values $(13.0 \%, 12.4 \%, 10.5 \%$, $8.4 \%$ ) are achieved for $s=1500 \mu \mathrm{m}$ and $a=120 \mu \mathrm{m} ; s=500 \mu \mathrm{m}$ and $a=70 \mu \mathrm{m} ; s=500 \mu \mathrm{m}$ and $a=120 \mu \mathrm{m}$; and $s=500 \mu \mathrm{m}$ and $a=170 \mu \mathrm{m}$; respectively. However, for each concentration value a large zone with near-optimum efficiency exists. For example:

- At x1 sun the front grid design with $s=3000 \mu \mathrm{m}$ and $a=370 \mu \mathrm{m}$ gives efficiencies of $12.8 \%$ (near at the optimum value of $13.0 \%$ ).

- At x2 suns, the geometry of the reference solar cell showed in Fig. 1, that is, fingers with $385 \mu \mathrm{m}$ width and separated $2.33 \mathrm{~mm}$ gives a good efficiency value of $12 \%$ (near at the optimum value of $12.4 \%$ ).

- For $\mathrm{x} 5$ and $\mathrm{x} 10$ suns, the reference solar cell front grid design $(s=2330 \mu \mathrm{m}$ and $a$ $=385 \mu \mathrm{m})$ is slightly shifted of the near-optimum efficiency region, see Fig. 7. For x5 suns, a good efficiency (10.4\%), near the optimum value $(10.5 \%)$, is achieved, for example, with $s=1500 \mu \mathrm{m}$ and $a=370 \mu \mathrm{m}$; and for $\mathrm{x} 10$ suns, a good efficiency $(8.3 \%)$, near the optimum value $(8.4 \%)$, is achieved with $s=1000 \mu \mathrm{m}$ and $a=370 \mu \mathrm{m}$. 
Therefore, if one keeps the width finger at $370 \mu \mathrm{m}$ which is a technological reasonable value, in order to achieve the optimum efficiency the separation between fingers has to diminish as the sun concentration increases: $s=3000 \mu \mathrm{m}$ at $\mathrm{x} 1$ sun, $s=2300 \mu \mathrm{m}$ at $\mathrm{x} 2$ suns, $s=1500 \mu \mathrm{m}$ at $\times 5$ suns, and $s=1000 \mu \mathrm{m}$ at $\times 10$ suns.

\section{Conclusions}

A physical 2D model for CIGS thin film solar cells has been developed. Information about the microstructure and composition is obtained by XRD and Raman Spectroscopy, in this way the effect of the Ga content in the absorber band gap can be properly considered.

Results demonstrate that if an optimized contact grid is used, efficiencies up to $8 \%$ can be obtained under $\times 10$ concentration instead of $6 \%$ for the reference cell. These results, using reference CIGS solar cells at industrial scale open interesting perspectives for new device arquitecture. Product cost should be reduced because under concentration smaller area cells can be used and smaller amounts of precursor materials are needed. It has been also demonstrated that the polycristalline structure of the CIGS technology and their inherent deffects do not represent one limitation to explore concentration concepts. 


\section{References}

Chelvanathan, P., Hossain, M.I., Amin, N., 2010. Performance analysis of copperindium-gallium-diselenide (CIGS) solar cells with various buffer layers by SCAPS. Current Appl. Phys. 10, 387-391.

Contreras, M.A., Ramanathan, K., AbuShama, J., Hasson, F., Young, D.L., Egaas, B., Noufi, R., 2005. Diode Characteristics in State-of-the-Art ZnO/CdS/Cu(In1-xGax)Se2 Solar Cells. Prog. Photovolt: Res. Appl 13, 209-216.

Decock, K., Khelifi, S., Burgelman, M., 2011. Analytical versus numerical analysis of back grading in CIGS solar cells. Sol. Energy Mater. Sol. Cells 95, 1550-1554.

Fontané, X., Izquierdo-Roca, V., Calvo-Barrio, L., Pérez-Rodríguez, A., Morante, J.R., Guettler, D., Eicke, A., Tiwari, A.N., 2009. Investigation of compositional inhomogeneities in complex polycrystalline $\mathrm{Cu}(\mathrm{In}, \mathrm{Ga}) \mathrm{Se}_{2}$ layers for solar cells. Appl. Phys. Lett. 95, 261912.

Gloeckler, M., 2005. Device Physics of Cu(In,Ga)Se2 Thin-film Solar Cells, Ph.D. thesis in Colorado State University.

Hack, B.M., Shaw, J.G., 1990. Numerical Simulations of Amorphous and Polycrystalline Silicon Thin-Film Transistors. Extended Abstracts 22nd International Conference on Solid-State Devices and Materials, Sendai, Japan. 999-1002.

Huang, C.H., 2008. Effects of $\mathrm{Ga}$ content on $\mathrm{Cu}(\mathrm{In}, \mathrm{Ga}) \mathrm{Se}_{2}$ solar cells sutdied by numerical modeling. J. of Phys. Chem. Solids 69, 330-334.

Jackson, P., Hariskos, D., Lotter, E., Paetel, S., Wuerz, R., Menner, R., Wischmann, W., Powalla, M., 2011. New world record efficiency for $\mathrm{Cu}(\mathrm{In}, \mathrm{Ga}) \mathrm{Se}_{2}$ thin film solar cells beyond 20\%. Prog. Photovolt: Res. Appl. 19, 894-897. 
Kaneshiro; J., Gaillard, N., Rocheleau, R., Miller, E., 2010. Advances in copperchalcopyrite thin films for solar energy conversion. Sol. Energy Mater. Sol. Cells, 94, 12-16.

Lárez, C., Bellaarba, C., Rincón, C., 1994. Alloy composition and temperatura dependence of the fundamental absorption edge in CuGaxIn1-xSe2. Appl. Phys. Lett. $65,1650-1652$.

Miskin, C.K., Yang W.C., Hages, C.J., Carter, N.J., Joglekarm, C.S., Stach, E.A., Agrawal, R., 2014. 9.0\% efficient $\mathrm{Cu} 2 \mathrm{Zn}(\mathrm{S}, \mathrm{Se}) 4$ solar cells from selenized nanoparticle inks. Prog. Photovolt: Res. Appl., DOI: 10.1002/pip.2472.

Mizrah, T., Adler, D., 1977. Indium-Tin-Oxide Silicon Heterojunction Photovoltaic Devices. IEEE Trans. on Elect. Devices 24, 458-462.

Niki, S., Contreras, M., Repins, I., Powalla, M., Kushiya, K., Ishizuka, S., Matsubura, K., 2010. CIGS absorbers and processes. Prog. Photovolt: Res. Appl. 18, 453-466.

Paire, M., Lombez, L., Pere-Laperne, N., Collin, S., Pelouard, J.L., Lincot, D., Guillemoles, J.F., 2011. Microscale solar cells for high concentration on polycrystalline $\mathrm{Cu}(\mathrm{In}, \mathrm{Ga}) \mathrm{Se} 2$ thin films. Appl. Phys. Lett. DOI: 10.1063/1.3604789.

Paire, M., Lombez, L., Donsanti, F., Jubault, M., Collin, S., Pelouard, J.J., Guillemoles, J.F., Lincot, D.; 2013. Cu(In,Ga)Se2 microcells: High efficiency and low material consumption, J. Renewable Sustainable Energy 5, 011202.

Ramanathan, K., Keane, J., Noufi, R., 2005. Properties of High-Efficiency CIGS ThinFilm Solar Cells. IEEE Photovoltaics Specialists Conference, Lake Buena Vista, Florida, 195-198.

Repins. I.L., Stanbery, B.J., Young, D.L., Li, S.S., Metzger, W.K., Perkins, C.L., Shafarman, W.N., Beck, M.E., Chen, L. Kapur, V.K., Tarrant, D., Gonzalez, M.D., Jensen, D.G., Anderson, T.J., Wang, X., Kerr, L.L., Keyes, B. Asher, S. Delahoy, A. 
Von Roedern, B.V., 2006. Comparison of Device Performance and Measured Transport Parameters in Widely-Varying Cu(In,Ga)(Se,S). Prog. Photovolt: Res. Appl. 14, 25-43.

Silvaco, 2013. Atlas User's Manual subsection 14.2, Simulating TFT devices. 738-739.

Silvaco, 2015. http://www.silvaco.com/products/device_simulation/atlas.html

Singh; U.P., Patra, S.P., 2010. Progress in Polycrystalline Thin-Film Cu(In,Ga)Se 2 Solar Cells. Int. J. of Photoenergy, doi:10.1155/2010/468147.

Ward, J.S., Ramanathan, K., Hasoon, F.S., Coutts, T.J., Keane, J., Contreras, M.A., Moriarty, T., Noufi, R. 2002. A 21.5\% efficient $\mathrm{Cu}(\mathrm{In}, \mathrm{Ga}) \mathrm{Se} 2$ thin-film concentrator solar cell. Progr. Photovolt: Res. Appl. 10, 41-16. 


\section{$\underline{\text { Figure captions }}$}

Fig. 1. Left, geometry and materials used for the solar cell modeling; right, SEM images of the solar cell used on the experimental characterization.

Fig. 2. Front CIGS solar cell geometry

Fig. 3. Detail of the XRD pattern of the solar cell used, showing the fitting of the CIGS (112) reflection with three contributions related to the response of absorber regions with different $\mathrm{Ga} /(\mathrm{In}+\mathrm{Ga})$ relative content (43\% reflection $1,61 \%$ reflection 2 , and $76 \%$ reflection 3 respectively).

Fig. 4. Raman shift of the A1 CIGS mode and their corresponding Ga content (left) and FWHM of the A1 CIGS mode (right).

Fig. 5. Left and right, real and imaginary semiconductor layers refraction index versus wavelength, respectively.

Fig. 6. I-V lighted results of simulated reference CIGS solar cell (lines) compared with measured of three random CIGS experimental solar cells (A - square marks-, B -circle marks-, and $\mathrm{C}$-triangle marks-), under four different levels of sun concentration $(1,2,5$, and 10).

Fig. 7. Efficiency maps versus finger width, a, and finger spacing, s for: a) 1 sun, b) 2 suns, c) 5 suns, and d) 10 suns concentrations.

\section{$\underline{\text { Table captions }}$}

Table 1. Semiconductor material characteristics used in the simulation.

Table 2. Experimental (solar cell B in Fig. 6) and simulated (using the model explained in section II) photovoltaic figures of merit under different levels of sun concentration $(\mathrm{x} 1, \mathrm{x} 2, \mathrm{x} 5$, and $\mathrm{x} 10)$.

Table 3. Simulated CIGS solar cell efficiency under low sun concentrations $(c=\mathrm{x} 1, \mathrm{x} 2$, $\mathrm{x} 5, \mathrm{x} 7 \mathrm{y}$ x 10 suns) for different number of buses $(n b=1,3,5$ y 7$)$ using two width fingers, $a(\mu \mathrm{m})$, for two values of finger separation, $s, 1000$ y $2500 \mu \mathrm{m}$. 


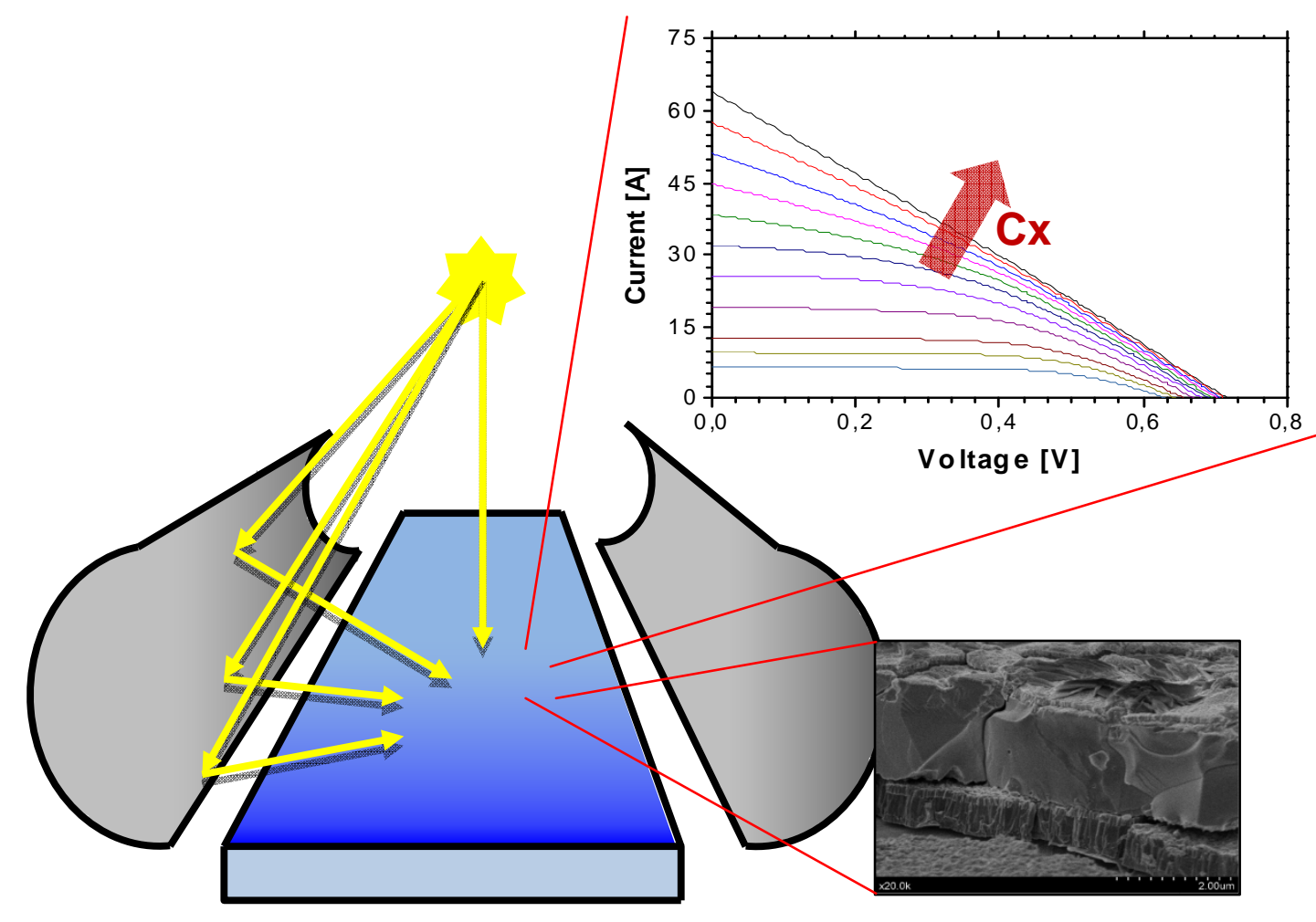




\section{Tables}

Table 1. Semiconductor material characteristics used in the simulation.

\begin{tabular}{llllll}
\hline Parameter & Unity & ITO & ZnO:Al & CdS & CIGS \\
\hline $\mathrm{N}_{\mathrm{D}} / \mathrm{N}_{\mathrm{A}}$ & $\mathrm{cm}^{-3}$ & $6.25 \mathrm{E}+19$ & $1.00 \mathrm{E}+18$ & $1.00 \mathrm{E}+17$ & $1.00 \mathrm{E}+16$ \\
$\varepsilon_{\mathrm{r}}$ & & 9 & 9 & 10 & 13.6 \\
$\mathrm{E}_{\mathrm{g}}$ & $\mathrm{eV}$ & 3.7 & 3.3 & 2.4 & $1.24-1.46$ \\
$\chi$ & $\mathrm{eV}$ & 4.6 & 4.6 & 4.4 & 4.48 \\
$\mathrm{~N}_{\mathrm{c}}$ & $\mathrm{cm}^{-3}$ & $2.20 \mathrm{E}+18$ & $2.20 \mathrm{E}+18$ & $2.20 \mathrm{E}+18$ & $2.20 \mathrm{E}+18$ \\
$\mathrm{~N}_{\mathrm{v}}$ & $\mathrm{cm}^{-3}$ & $1.80 \mathrm{E}+19$ & $1.80 \mathrm{E}+19$ & $1.80 \mathrm{E}+19$ & $1.80 \mathrm{E}+19$ \\
$\tau_{\mathrm{n}, \mathrm{eff}}$ & $\mathrm{S}$ & $1.00 \mathrm{E}-07$ & $1.00 \mathrm{E}-07$ & $1.00 \mathrm{E}-07$ & $1.00 \mathrm{E}-07$ \\
$\tau_{\mathrm{p}, \mathrm{eff}}$ & $\mathrm{S}$ & $1.00 \mathrm{E}-07$ & $1.00 \mathrm{E}-07$ & $1.00 \mathrm{E}-07$ & $1.00 \mathrm{E}-07$ \\
$\mu_{\mathrm{n}}$ & $\left(\mathrm{cm}^{2}\right) /(\mathrm{V} \cdot \mathrm{s})$ & 100 & 100 & 100 & 50 \\
$\mu_{\mathrm{p}}$ & $\left(\mathrm{cm}^{2}\right) /(\mathrm{V} \cdot \mathrm{s})$ & 25 & 25 & 25 & 20 \\
$D$ Defect type & & donor & donor & acceptor & donor \\
$\mathrm{N}_{\mathrm{GD}} / \mathrm{N}_{\mathrm{GA}}$ & $\mathrm{cm}^{-3}$ & $1.00 \mathrm{E}+17$ & $1.00 \mathrm{E}+17$ & $1.05 \mathrm{E}+18$ & $1.00 \mathrm{E}+14$ \\
$\mathrm{E}_{\mathrm{GD}} / \mathrm{E}_{\mathrm{GA}}$ & $\mathrm{eV}$ & 1.85 & 1.65 & 1.2 & 0.575 \\
$\mathrm{w}_{\mathrm{GD}} / \mathrm{w}_{\mathrm{GA}}$ & $\mathrm{eV}$ & 0.1 & 0.1 & 0.1 & 0.1 \\
$\sigma_{\mathrm{eGD}} / \sigma_{\mathrm{eGA}}$ & $\mathrm{cm}^{2}$ & $1.00 \mathrm{E}-12$ & $1.00 \mathrm{E}-12$ & $1.00 \mathrm{E}-17$ & $5.00 \mathrm{E}-13$ \\
$\sigma_{\mathrm{hGD}} / \sigma_{\mathrm{hGA}}$ & $\mathrm{cm}^{2}$ & $1.00 \mathrm{E}-15$ & $1.00 \mathrm{E}-15$ & $1.00 \mathrm{E}-12$ & $1.00 \mathrm{E}-15$ \\
\hline
\end{tabular}

Table 2. Experimental (solar cell B in Fig. 6) and simulated (using the model explained in section II) photovoltaic figures of merit under different levels of sun concentration (x1, x2, x5, and $\mathrm{x} 10)$.

\begin{tabular}{lllllllll}
\hline & \multicolumn{2}{c}{ x1 } & \multicolumn{3}{c}{ x2 } & \multicolumn{2}{c}{ x5 } & \multicolumn{2}{c}{ x10 } \\
& Modeling & Exp. & Modeling & Exp. & Modeling & Exp. & Modeling & Exp. \\
\hline Voc (V) & 0.62 & 0.63 & 0.66 & 0.66 & 0.70 & 0.69 & 0.73 & 0.71 \\
Isc (A) & 6.06 & 6.41 & 12.13 & 12.93 & 30.20 & 45.94 & 58.96 & 68.18 \\
FF (\%) & 67.31 & 65.69 & 61.76 & 57.07 & 45.79 & 28.86 & 29.16 & 24.78 \\
Eff (\%) & 12.13 & 12.65 & 11.75 & 11.55 & 9.26 & 8.73 & 6.00 & 5.75 \\
\hline
\end{tabular}


Table 3. Simulated CIGS solar cell efficiency under low sun concentrations $(c=$ $\mathrm{x} 1, \mathrm{x} 2, \mathrm{x} 5, \mathrm{x} 7 \mathrm{y}$ x10 suns) for different number of buses $(n b=1,3,5$ y 7$)$ using two width fingers, $a(\mu \mathrm{m})$, for two values of finger separation, $s, 1000$ y $2500 \mu \mathrm{m}$.

\begin{tabular}{llllllllllllll}
\hline Concentration & $c$ & \multicolumn{2}{c}{$\mathrm{x} 1$} & \multicolumn{2}{c}{$\mathrm{x} 2$} & \multicolumn{2}{c}{$\mathrm{x} 5$} & \multicolumn{2}{c}{$\mathrm{x} 7$} & \multicolumn{2}{c}{$\mathrm{x} 10$} \\
\hline & $s$ & 1000 & 2500 & 1000 & 2500 & 1000 & 2500 & 1000 & 2500 & 1000 & 2500 \\
& $a$ & 70 & 220 & 120 & 370 & 220 & 670 & 270 & 870 & 370 & 970 \\
$n b$ & 1 & 8.58 & 9.31 & 7.83 & 8.27 & 5.97 & 5.96 & 5.18 & 5.13 & 4.54 & 4.04 \\
$n b$ & 3 & 12.58 & 12.55 & 12.00 & 11.75 & 10.20 & 9.55 & 9.22 & 8.34 & 8.08 & 6.90 \\
$n b$ & 5 & $\mathbf{1 2 . 7 0}$ & $\mathbf{1 2 . 5 9}$ & $\mathbf{1 2 . 1 7}$ & $\mathbf{1 1 . 8 5}$ & $\mathbf{1 0 . 4 8}$ & $\mathbf{9 . 7 7}$ & $\mathbf{9 . 5 5}$ & $\mathbf{8 . 5 7}$ & $\mathbf{8 . 4 0}$ & $\mathbf{7 . 1 6}$ \\
$n b$ & 7 & 12.56 & 12.43 & 12.04 & 11.71 & 10.43 & 9.70 & 9.53 & 8.53 & 8.39 & 7.15 \\
\hline
\end{tabular}



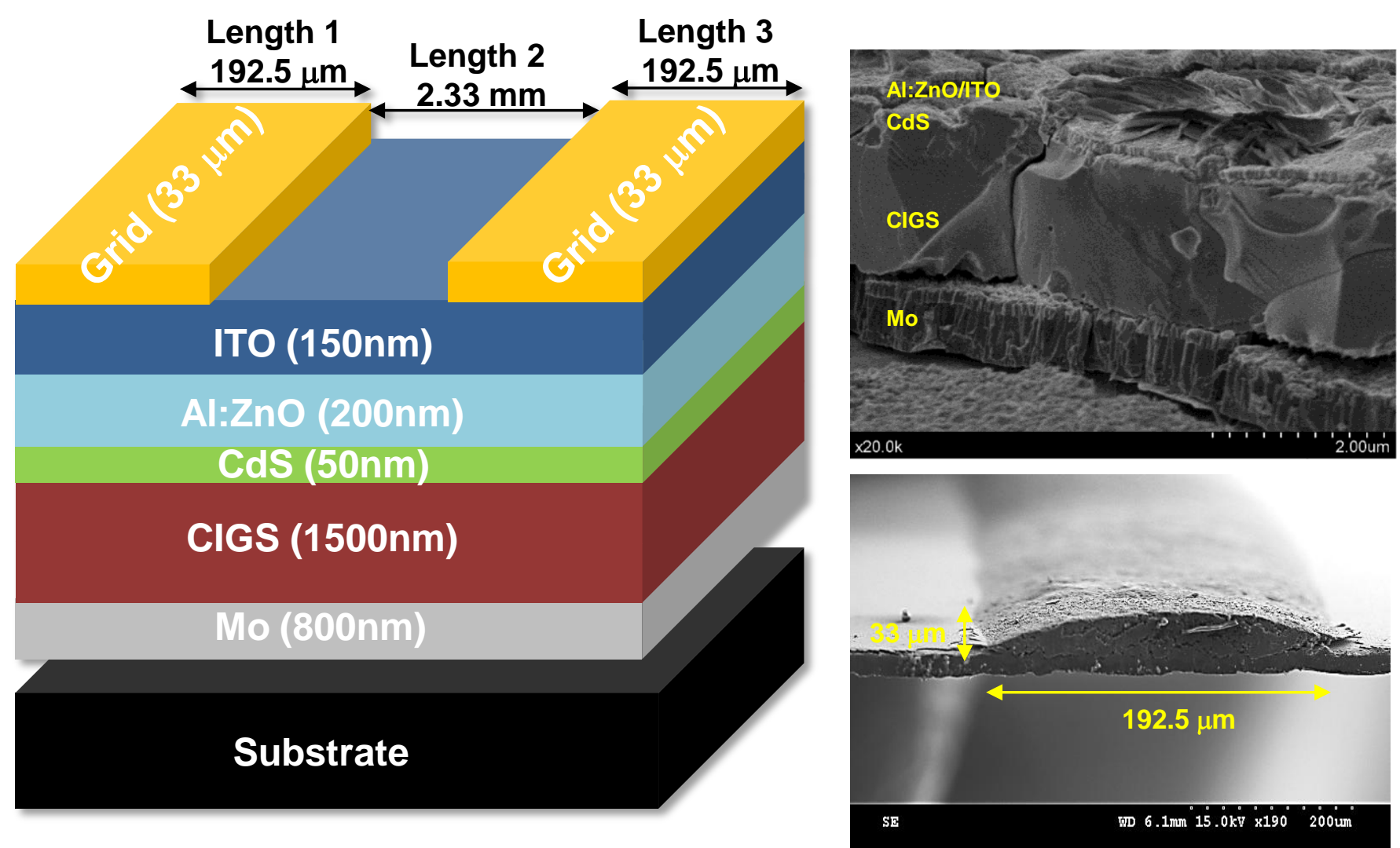


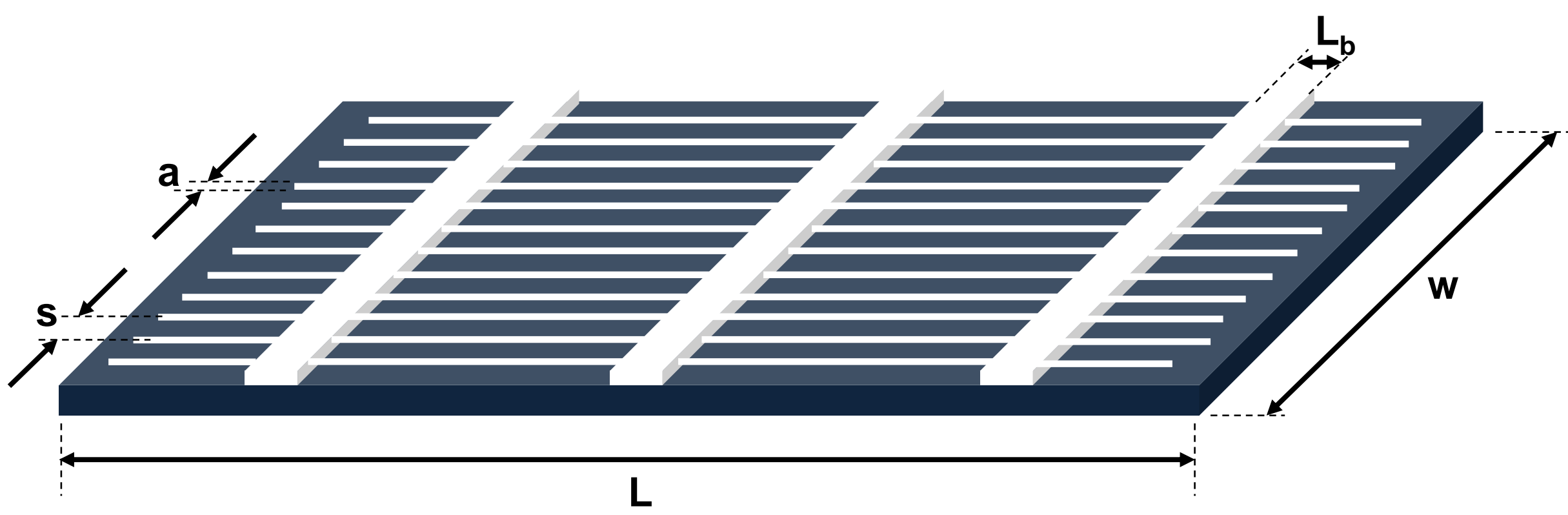




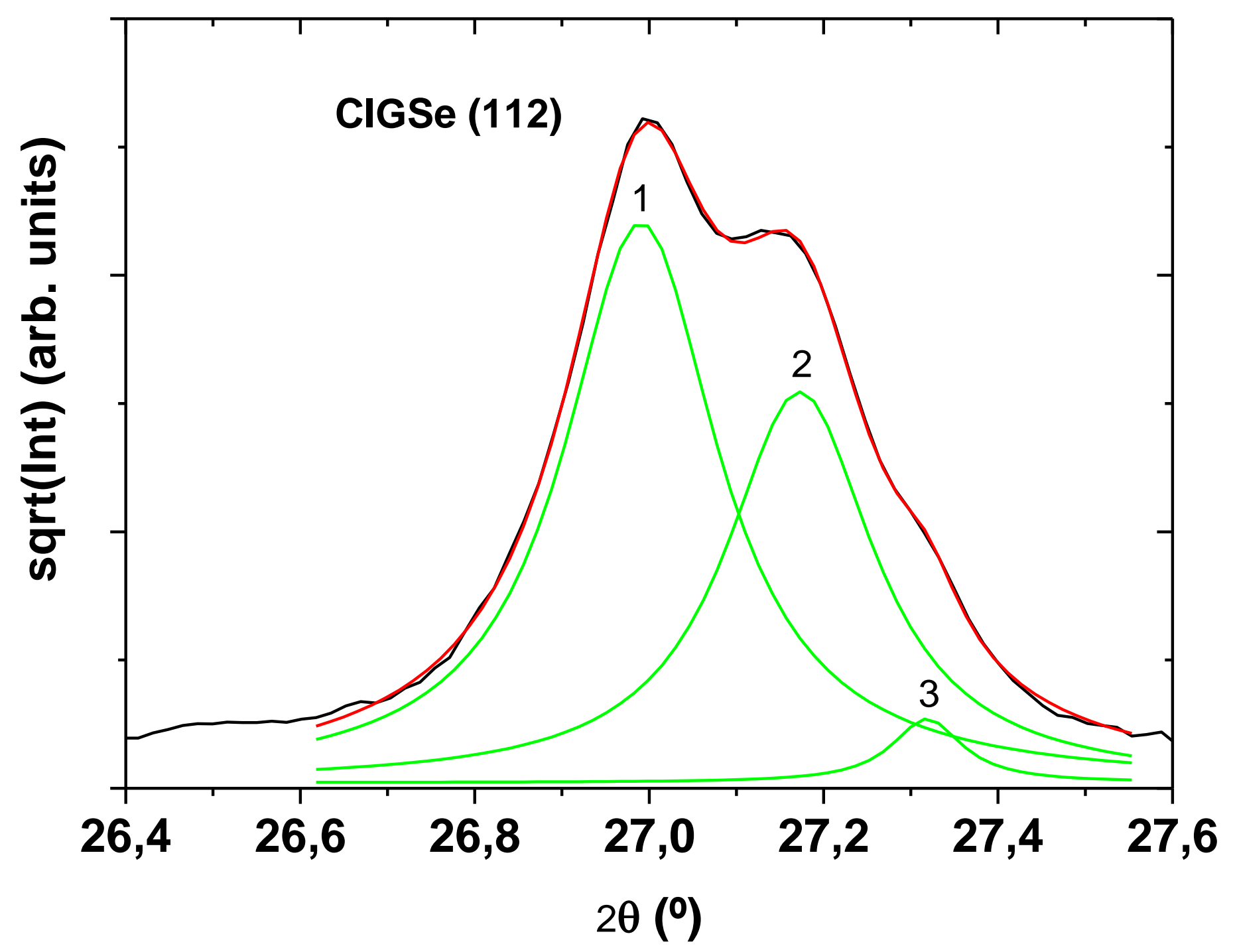



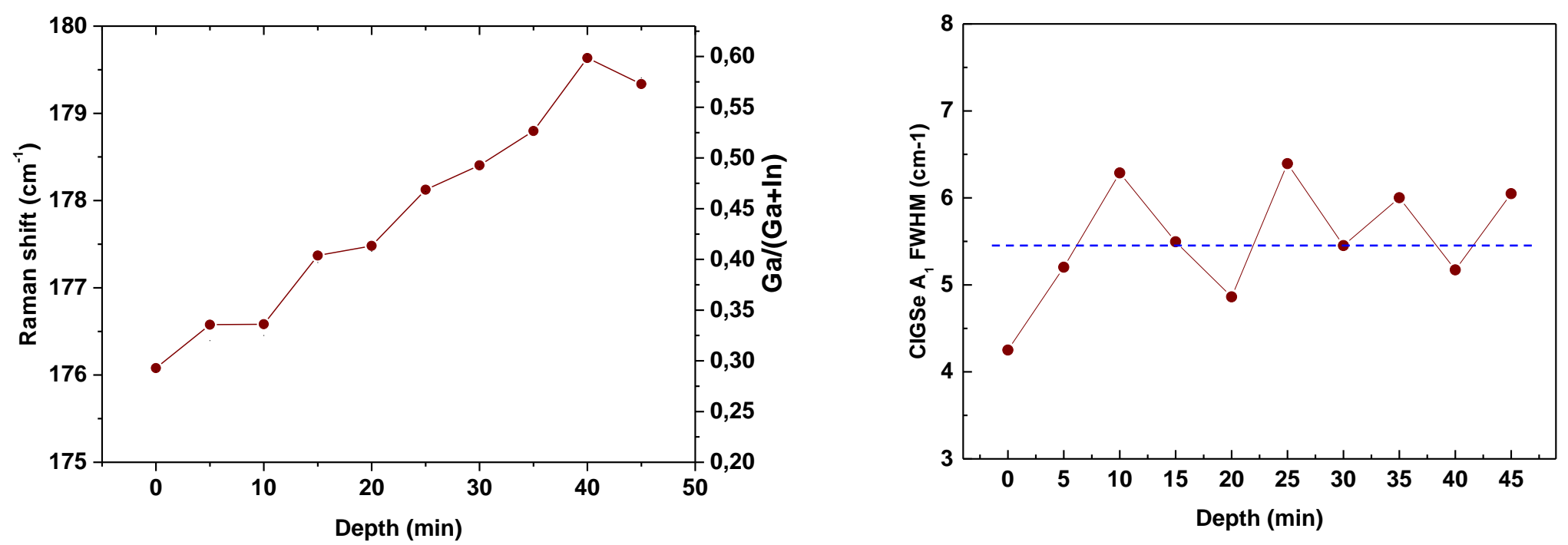

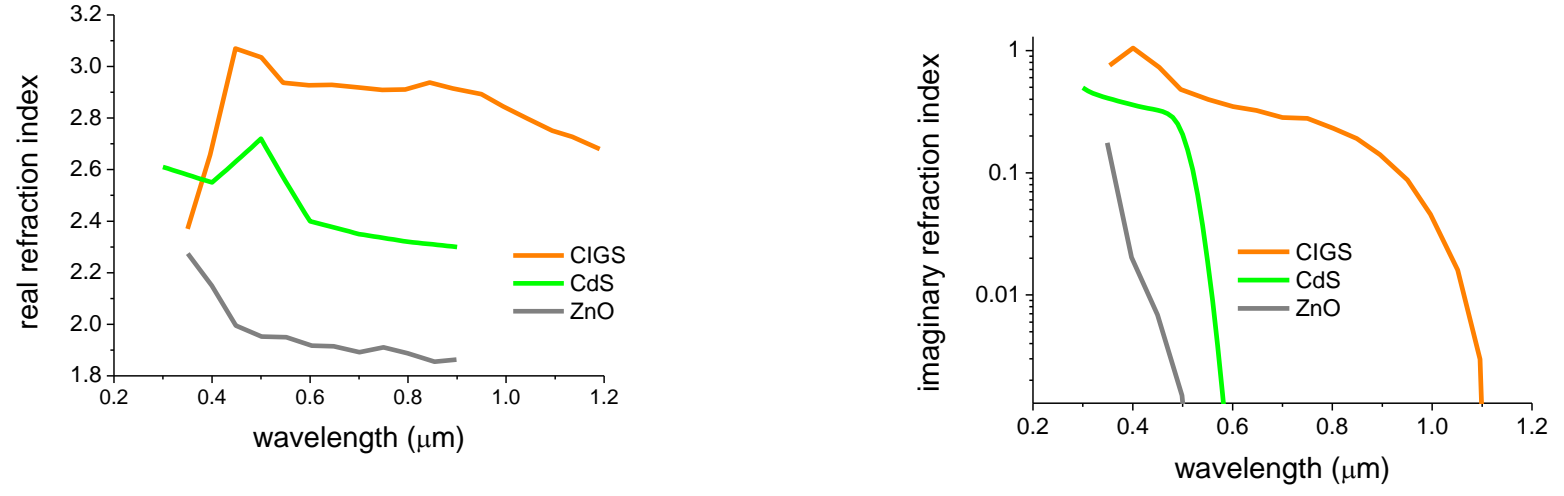


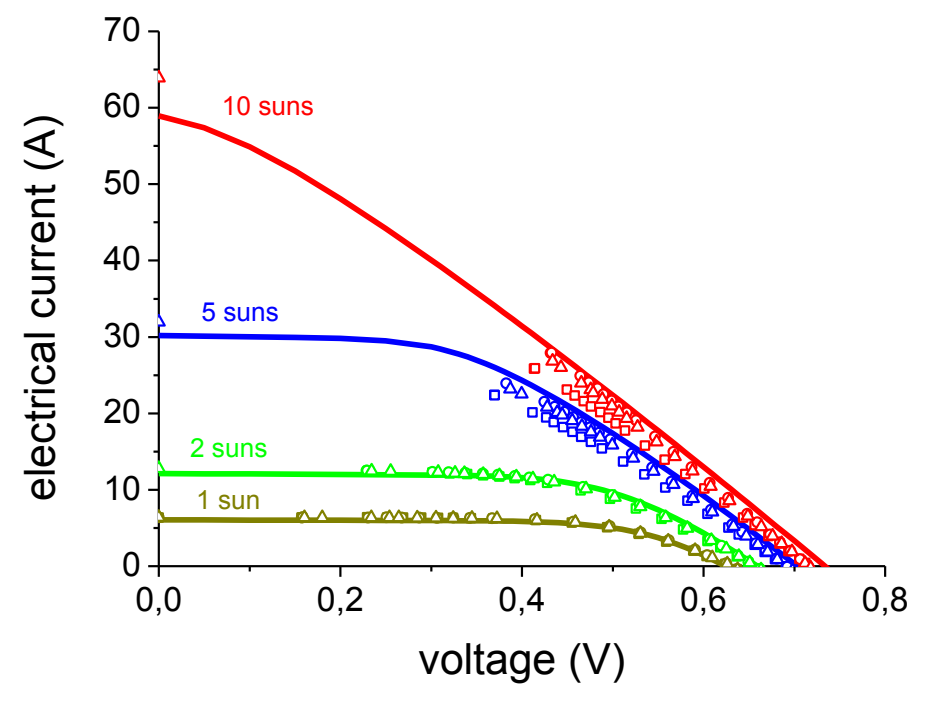



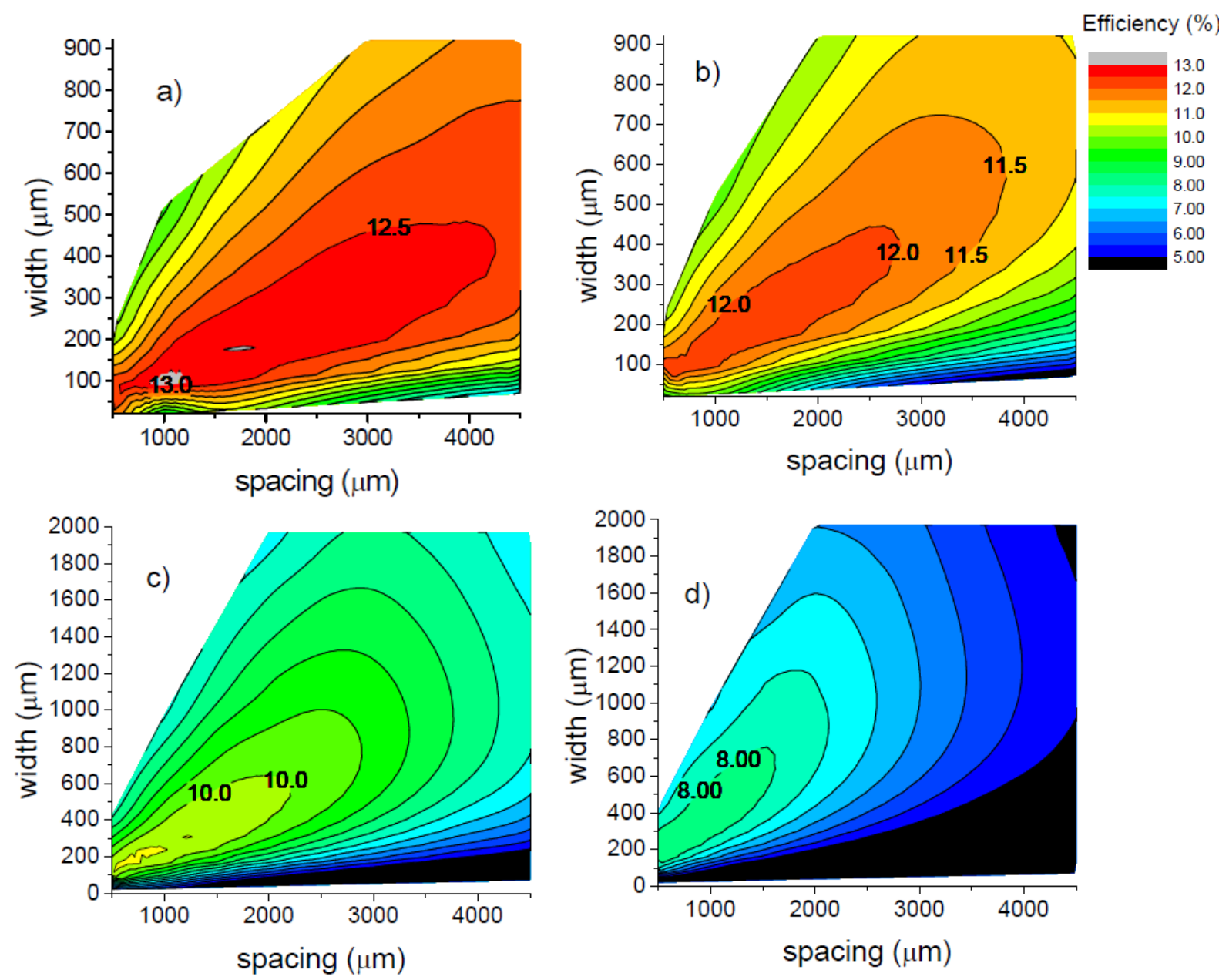